\title{
Participación comunitaria y gobiernos locales en Cuba. La experiencia de los Consejos Populares y el impacto de las reformas de Raúl Castro
}

Promovida por instituciones, asociaciones y movimientos vecinales, la participación comunitaria transcurre en el espacio local, estrechamente vinculada a la cultura política ${ }^{1}$ y a identidades colectivas que se expresan a escala barrial. Lo comunitario puede cimentar un sentido de pertenencia individual

Este texto analiza el estado de la participación comunitaria en un Consejo Popular de La Habana, Cuba. El trabajo de campo fue desarrollado en varias etapas, utilizando métodos de investigación cualitativa que hacen énfasis en los discursos y prácticas de los actores. Finalmente, comentamos el impacto de las recientes reformas gubernamentales en el desarrollo municipal y la acción local.

Palabras claves: participación, comunidad, desarrollo local, reformas, Cuba.

- Profesor-investigador del Departamento de Gestión Pública y Desarrollo, División de Ciencias Sociales y Humanidades, Universidad de Guanajuato, campus León. xarchano@gmail.com

- Estudiante de la maestría en Sociología de la Universidad Iberoamericana de la Ciudad de México.

ljgalv@gmail.com hacia el entorno cotidiano y favorecer la toma de conciencia sobre comportamientos ciudadanos responsables y efectivos. Este texto constituye una aproximación al desempeño y representaciones en torno a la participación comunitaria en Cuba, a partir de la experiencia de un Consejo Popular (CP) de la periferia capitalina, a la luz de las transformaciones estructurales y funcionales en marcha en el archipiélago antillano.

Retomamos los resultados de una investigación anterior (abril-

I. Entendemos la cultura política como la combinación de representaciones, significados, valores, convicciones, expectativas y actitudes; en suma, esquemas y construcciones simbólicas acerca de la política, los cuales, mediante un proceso dialéctico de internalización/externalización, guían y otorgan sentido social a la actuación individual en la esfera pública. 
junio de 2008), orientada a caracterizar el estado de la participación comunitaria en Cuba, en el barrio de Alamar, en Ciudad de la Habana, a partir del estudio de entidades locales relevantes, en especial un Taller de Transformación Integral del Barrio (TTIB) y un CP, ambas instancias subordinadas al Gobierno Municipal. Tres años después (agosto-noviembre de 2011), fue realizada una segunda aproximación al fenómeno, concentrada en el CP y en el TTIB. $^{2}$

En ambas etapas se emplearon la observación participante y la entrevista en profundidad, técnicas de la investigación cualitativa. La primera nos permitió interactuar con los informantes en su espacio de vida cotidiana, y recoger valiosos datos de modo sistemático y no intrusivo. Por su parte, como vía de acceso a los senderos de la subjetividad humana, aprovechamos de la entrevista, entre otras virtudes, su gran flexibilidad y capacidad de reacción ante la emergencia de datos no previstos inicialmente. La reconstrucción lingüística y paralingüística de las entrevistas arrojó información amplia, veraz y confiable sobre la dimensión simbólica del objeto de estudio.

A lo largo de este acercamiento fueron entrevistados, algunos por partida doble: tres miembros de la dirección del CP, dos delegados de circunscripción, dos especialistas del TTIB, así como una delegada-diputada y dos líderes comunitarios -diez en total-. Además de los resultados de dichas entrevistas en profundidad a figuras prominentes de la gestión local, incorporamos la información aportada por otras cuarenta y ocho entrevistas semiestructuradas -anónimas- practicadas a vecinos de la comunidad; así como las observaciones registradas como fruto de la participación en tres asambleas de rendición de cuentas del CP.

2. En la primera etapa del trabajo fue decisivo el aporte de la colega Djanamé Dabelcourt. Resultados obtenidos en los dos momentos fueron publicados en Chaguaceda, Daubelcour y González (20I2). 
Todo ello, como hemos anotado, en ambas fases del trabajo de campo, 2008 y 2011.

A todos estos actores se les pidió que valoraran la participación propia y la de los vecinos en la localidad, la eficiencia de los mecanismos establecidos para resolver los problemas, y el impacto en su vida personal y en el barrio de los cambios promovidos por el presidente Raúl Castro en años recientes. Se les interrogó, asimismo acerca de sus motivaciones, actitudes y asunciones en torno a la participación. En el caso de los directivos del CP y el TTIB, añadimos preguntas específicas sobre su desempeño en el cargo -logros y carencias-, la relación entre las diferentes instancias comunitarias y sus representaciones personales.

Por último, hemos de destacar que, en este artículo, reanalizamos la problemática investigada bajo el contexto de las reformas acometidas durante el gobierno del presidente Raúl Castro.

\section{Referentes teóricos}

Antes de sumergirnos en el tema, proponemos trazar un esbozo teórico de la participación, un concepto bastante polémico y heterogéneo en las teorías política y sociológica contemporáneas.

Comenzaremos afirmando el carácter multidimensional de la participación, no sólo por subdividirse en fases relacionadas con el grado de acceso a las decisiones, sino por su capacidad de expresarse en disímiles esferas, que van desde la economía y la política hasta el mundo del arte. También porque se concreta en marcos específicos de organización social -formalizados o no-, tales como el político-institucional, el laboral, el asociativo y el familiar; los cuales, en su conjunción, delimitan el sentido, la intensidad, periodicidad, los niveles y objetivos de la participación. 
Así, en los marcos de este trabajo, definiremos a la participación ciudadana, de forma amplia, como el involucramiento activo y plural de la ciudadanía (individuos y colectividades) en un conjunto de acciones (expresión, deliberación, creación de espacios de organización, disposición de recursos) en el control de las instituciones estatales y partidarias, el desarrollo, ejecución y evaluación de las políticas públicas, y en diversas formas de organización social e incidencia pública generados en y desde la sociedad civil.

Ahora bien, toda participación encierra un sentido político -simbólico y práctico-, así como un vínculo con el poder, categoría convertida a la vez en causa y fin de su existencia. Más allá de cualquier visión convencional de participación desplegada en las estructuras clásicas del sistema político (partidos, parlamentos, etc.), lo participativo supone, normativamente, el deseo de algunos sujetos de compartir las decisiones fundamentales de un proyecto. Específicamente, los procesos relativos a la cultura y la participación políticas se inscriben dentro del vasto rejuego de las relaciones de dominación y obediencia. La acción política responde a una cultura política permanentemente reconstruida -activada en determinadas situaciones-, y a un complejo motivacional íntimamente conectado con un sistema de necesidades más o menos concientizadas. Como componente central de la democracia, la participación es efectiva cuando transfiere cuotas amplias de autoridad a los sectores marginados del poder para que rompan voluntariamente "la relación asimétrica de sumisión y dependencia integrada en el binomio sujeto-objeto" (Fals, 2001, p. 31). Sin embargo, en tanto cualquier modificación de las relaciones de poder conlleva reacciones de resistencia por parte de las élites dominantes -que "reacomodan" las esencias del proceso a sus intereses hegemónicos-, entendemos que "Los procesos participativos no pueden estar ajenos a las contradicciones, 
de las que emergen y las que a su vez provocan" (Rebellato, 2005, p. 474).

Una participación activa comienza por la toma de conciencia del rol que debemos asumir como agentes transformadores; estrechamente acompañada por la autoorganización -espontánea o bajo asesoramiento-, el análisis crítico y la definición de las necesidades y problemas. En un segundo momento ocurre el intercambio de opiniones, la articulación de los objetivos y se perfilan acciones con base en la disponibilidad de recursos. La ejecución es el colofón, marcado por continuas evaluaciones y controles de la gestión concreta.

Este continuum implica "tomar decisiones y no simplemente ser ejecutor de algo, es ser sujeto en todo un proceso" (Kisnerman N. et al. en D’Angelo, 2004, p. 86.). Así, la hora de determinar los sentidos del acto participativo, "no sólo como beneficiarios sino también como formuladores de estas decisiones" (Domínguez y Lutjens, 2004, p. 235), es el eje inalienable de la participación y, en efecto, el más soslayado por las propuestas pseudoparticipativas de corte asistencialista, tecno-burocrático y elitista.

Para el abordaje del estado de la participación partimos de considerar que tal fenómeno se nutre de las diversas culturas (complejos de ideas, valores y creencias) participativas que sus integrantes poseen. Forjadas desde la interacción entre diversas experiencias personales (componente psicológico) y proyectos políticos (factor ideológico), la mirada a estas culturas participativas permite comprender cómo los discursos y prácticas "dominantes" son incorporados, transformados o desafiados por las prácticas de los actores; cómo emergen formas alternativas de concebir la participación y el liderazgo dentro y fuera de la organización. De forma que la heterogeneidad de legados y su hibridación en prácticas y procesos específicos dejan su huella en la conformación de las culturas participativas de todos los actores colectivos; culturas que ponen en relación ideales, valores, represen- 
taciones y prácticas sobre "cómo participar" que tributan tanto al fortalecimiento de la ciudadanía -como las que se relacionan con la autonomía, la autogestión y la solidaridad-como a la reproducción de elementos que fortalecen la dominación política y la exclusión social.

Además, la participación se materializa a través de ciertas estructuras o conjunto de espacios organizativos más o menos estables (asambleas, coordinaciones, etc.), reglas (formales o informales) y recursos (materiales y/o simbólicos) que "dan vida" a las diversas modalidades (directa, delegada, activismo, entre otras) de la organización interna y la incidencia externa. Sólo a partir de su existencia (y en arreglo con las culturas participativas vigentes) se desarrollan las dinámicas, o conjunto de acciones secuenciadas mediante las que los individuos y grupos específicos despliegan la acción de participar, dando cuenta de la secuencia (y evolución) de sus agendas, respuestas y estrategias para definir y defender sus espacios sociales, fronteras culturales y posiciones políticas dentro y fuera de la sociedad civil y el espacio público. De tal suerte, si la cultura identifica el elemento subjetivo -e intersubjetivo- del fenómeno participativo, con las estructuras ubicamos el sustrato material y organizacional del mismo y con las dinámicas el componente cronológico; disponiendo de una suerte de mapa para el abordaje de esta compleja problemática.

\section{Introducción a la participación comunitaria en Cuba}

La participación -y su relación con los actores institucionales y sociales- ha motivado acercamientos de los investigadores cubanos desde los años noventa, dentro de los cuales destacan algunos aportes particulares. ${ }^{3}$ Sin embargo, 
la academia cubana, poseedora de una calidad incontestada en el Caribe insular, no emula en este tema con sus más sustanciosos abordajes sobre las desigualdades sociales y territoriales, el racismo y los conflictos generacionales. La naturaleza notablemente política del objeto de estudio, ha jugado una mala pasada a los interesados en el tema y favorecido su tratamiento epidérmico.

En el terreno práctico, la participación adquiere una connotación especial en Cuba tras el triunfo de la Revolución, momento y movimiento de cambio políticos asociados a la restitución de los derechos de las grandes mayorías, secuestrados por la dictadura de Fulgencio Batista. Desde 1959, se multiplicaron los roles de participación, de manera que cada ciudadano fuera a la vez combatiente, miembro de las organizaciones de masas y políticas, activista sanitario, etc. Dentro del régimen socialista de Estado, que se construyó desde entonces, emergió paulatinamente un modelo de participación que combinaba grandes congregaciones populares con la ejecución centralizada del liderazgo y el bloqueo institucional a la autoorganización ciudadana.

Para la década de los setenta se conformó el Poder Popular, un sistema de gobierno que abarcaba desde la localidad (Asamblea y Gobierno municipales), pasando por la provincia (Asamblea y Gobierno provincial), hasta llegar al nivel nacional (Asamblea Nacional o Consejo de Estado). Dentro de este sistema político, los CP constituyen una pieza clave, surgidos en 1988, a partir de la recomendación del III Congreso del Partido Comunista de Cuba (PCC), celebrado en 1986. La Ley 91, aprobada por la Asamblea Nacional del Poder Popular en el año 2000, define al CP como un órgano del Poder Popular, local, de carácter participativo, investido de la más alta autoridad para el desempeño de sus funciones. Deviene un actor controlador, fiscalizador y coordinador de los numerosos factores de la comunidad (García, 1998), que apoya a su órgano inmediato superior, 
la Asamblea Municipal, en la tarea de conocer y atender las necesidades y los intereses de sus habitantes.

Cada CP abarca a varias circunscripciones. Y los delegados electos en dichas circunscripciones forman parte de la estructura del CP; los otros miembros son representantes designados por las organizaciones de masas, las instituciones y entidades de mayor importancia en la zona, lo cual asegura un cierto nivel de representación del tejido institucional y social de la comunidad. La elección del presidente y de los vicepresidentes se produce por votación de los miembros del CP.

$\mathrm{Al}$ ser el $\mathrm{CP}$ un órgano colectivo, ciertas decisiones se toman por voto, una práctica que suele dar voz en las acciones gubernamentales a instituciones que no han sido electas dentro de las estructuras del Poder Popular. Estas características lo convierten en un espacio potencialmente útil para una representación y participación amplias de los intereses comunitarios. No obstante, los CP corren el riesgo de convertirse en "una instancia más" cuando al empobrecimiento de su gestión comunitaria y la dilución del accionar colectivo en un exceso de reuniones, se suma la asunción de funciones administrativas por parte de algunos consejos, la tendencia constatable a concentrar facultades en el presidente y trastocar funciones entre el Consejo y las organizaciones de masas, superponiendo su accionar.

\section{Mapeando el contexto y sus espacios}

Alamar es un barrio obrero fundado el 17 de febrero de 1971, en la periferia de la capital, en el actual municipio Habana del Este. En 1994, con la reestructuración de los CP, se crearon en esta zona dos de ellos: el primero, Alamar Este, resulta el CP de mayor extensión del país, con 9.2 $\mathrm{km}^{2}$; comprende a veintiocho circunscripciones y, sumada la población flotante, los residentes llegan casi a 43000 , 
padrón similar al de varios municipios. Como "cuasi" municipio, reúne los atributos que definen a estas entidades: un territorio, una población, determinadas instancias de gobierno y capacidades económicas, todo ello dentro de fines de promoción del desarrollo y convivencia ciudadanos (Valencia, 2013).

El presidente coordina todo el trabajo del CP, para lo cual mantiene su comunicación con los delegados, los otros CP y la Asamblea Municipal. De acuerdo con Adonis García, presidente del CP Alamar Este: "La gestión del CP Alamar Este es controlar y fiscalizar todo el trabajo que se hace dentro de nuestros límites. Todas las organizaciones y entidades, la población, etc." (entrevista personal, 2008). El CP puede beneficiarse de un poder que le confiere la Ley 91: "podemos llegar hasta los ministros y el presidente de la República, en caso de una situación muy especial, que a nivel municipal no tenga respuesta" (entrevista personal, 2008). Sin embargo, la práctica demuestra que se trata de un poder fundamentalmente formal, no empleado.

Respecto al funcionamiento del CP, Blanca Ballester, delegada de circunscripción y diputada a la Asamblea Nacional, tiene su propia visión y ha propuesto cambios:

El Poder Popular surgió hace cuarenta años, hay que realizar transformaciones en todos los sentidos, como señaló Raúl [Castro]. Incluso, él dijo que habrá que modificar la Constitución, para atemperar el sistema electoral y el funcionamiento de las asambleas. Es preciso reformar la estructura de gobierno, separar las funciones empresariales de las gubernamentales, que realmente el presidente de cada Asamblea responda a las problemáticas de su territorio (entrevista personal, 20II). 


\section{El TTIB: una fuente de cultura participativa}

El CP Alamar Este ha mantenido lazos estrechos y muy particulares con el TTIB $^{4}$ homónimo, fundado el 12 de mayo de 1998 con la misión de transformar la comunidad con la participación de los vecinos, organizaciones políticas y entidades económicas del territorio (Pupo y Santana, 2005). La actual presidenta del CP da fe del vínculo de su entidad con el quehacer del TTIB:

Nuestras relaciones con el Taller son magníficas. La escuela de delegados la imparten ellos. Allí he aprendido de todo. $Y$ he visto los frutos, sobre todo en herramientas para acercarme mejor a las personas y enfrentar distintos problemas en la comunidad (entrevista personal, 20I I).

Según la delegada y diputada a la Asamblea Nacional, mientras ocupó el cargo de presidenta del Consejo (mayo de 2005-marzo de 2008) el asesoramiento de los especialistas del TTIB le ayudó mucho.

En el Taller pasé cursos de liderazgo, Metodología para la Educación Popular, ${ }^{5}$ entre otros. Todo eso promueve el empleo de técnicas de participación. No se trata de hacer la rendición de cuentas fríamente, sino de poner en práctica dinámicas y técnicas participativas, didácticas, donde las personas no vean la reunión como una cosa impuesta (entrevista personal, 20II).

Por su parte, Andrea del Sol, especialista principal del TTIB y delegada de Circunscripción, asegura que "la diferencia entre los delegados egresados del Taller y el resto es grande.

4. Para el estudio de la experiencia de los TTIB ver AA.VV., 1998 y AA.VV., 2006. 5. Más allá de su retórica atractiva, la experiencia cubana con la Educación Popular no ha logrado convertirse en principio regenerador de una pedagogía libertaria, al ser confinada a pequeñas comunidades y al evadir sus promotores el análisis de los factores estructurales que reproducen el autoritarismo, dentro y fuera de los ámbitos asociativo y local.

\section{4}


Participación comunitaria y gobiernos locales en Cuba. La experiencia de los Consejos Populares y el impacto de las reformas de Raúl Castro

Quienes han pasado estas escuelas son hoy 'otros delegados' (entrevista personal, 2011).

Luis Sosa Silva, un líder informal de la comunidad reconoce la profunda huella que ha dejado el TTIB en su vida: "La gente que se vincula al Taller adquiere otra cultura, otra visión, otras motivaciones. De lo que he aprendido allí, una de las herramientas que más me gusta usar es la tormenta de ideas" (entrevista personal, 2011).

Sin embargo, sus propios impulsores expresan críticas. Según Andrea del Sol:

En la misión inicial del TTIB hay un acápite sobre la transformación integral de la comunidad; y no hemos avanzado en la evolución física, en todo lo relacionado con rehabilitar, reanimar [...] Eso lleva una cuota grande de recursos materiales que no tenemos. Lo que hacemos es promover, acompañar $y$ asesorar iniciativas locales, servir de mediadores entre instituciones y el Gobierno (entrevista personal, 20I I).

\section{Hablan los actores: visiones laxas de la participación}

En 2008, Blanca Ballester Santos, una líder barrial consideraba que la participación en la demarcación se había diversificado. Tres años después, afirmó:

la participación todavía no es lo suficientemente buena en la comunidad. Necesita de algún mecanismo que la rescate. Hay mil maneras de estimular la participación, tiene que haber interés y solidaridad, o sea, que las personas se identifiquen con los problemas de los demás (entrevista personal, 20I I).

Aunque algunos líderes, como el doctor Luis Sosa y el delegado Mario Fraga Rojas, califican la participación de los vecinos en la comunidad de "buena"; otros, como la delegada y especialista principal del TTIB acotan: 
Actualmente las personas no participan en la toma de decisiones de la comunidad. Los vecinos casi nunca se enteran de las decisiones. Pasa aquí y en muchas partes. La gente no siente que se le toma en cuenta; se involucran cuando hablamos de resolver sus propias necesidades, pero estamos muy lejos de lograr una participación genuina (entrevista personal, 20II).

En cuanto a la cultura participativa de los ciudadanos de este CP, Andrea del Sol comenta que falta mucho por hacer:

El taller no alcanza para capacitar ni siquiera a la mitad de los pobladores. Además, según un estudio comunitario realizado en 1996, aquí viven personas de más cincuenta municipios del país. $O$ sea, el CP no es un consejo tradicional donde los vecinos nacen $y$ crecen, $y$ tienen un alto sentido de pertenencia (entrevista personal, 20II).

Definir operativamente la participación, para dialogar con la información recabada, nos conduce a desglosar el término en tres modalidades básicas: 1) formar parte, es decir pertenecer a una colectividad; 2) tener parte, asumir alguna función dentro del todo; 3) tomar parte, decidir, lo cual completa la idea de lo participativo, con la conciencia de que se puede y debe incidir en el curso de los acontecimientos (Rebellato, 2005).

Del trabajo de campo se desprende que la población de Micro X consultada, así como los representantes entrevistados, tienen una concepción muy difusa del término. $\mathrm{Al}$ preguntar acerca de la concepción sobre la participación en el propio trabajo de la dirección del CP, y su interacción con la comunidad, los entrevistados inmediatamente recurren al ejemplo de las asambleas de rendición de cuentas, las cuales tienen lugar cada seis meses.

Los cuestionamientos a la calidad de la participación y sus representaciones en el imaginario popular son visibles. Para Mercedes Galán Tamayo, una activista local: 
Participación comunitaria y gobiernos locales en Cuba. La experiencia de los Consejos Populares y el impacto de las reformas de Raúl Castro

en general, los cubanos no conocen realmente el concepto de participación. Cuando hacemos diagnósticos con adultos, y les preguntamos: ¿Usted participa en las rendiciones de cuentas?' Rápidamente responden: 'Sí, porque yo voto'. Pero, ¿es participar ir y levantar la mano? (entrevista personal, 20II).

El acto de participar con frecuencia se asocia al de asistir, estar presente, o simplemente apoyar, opinar, intervenir, particularmente según algunos integrantes del Consejo Popular y líderes barriales. La propia presidenta del CP, Yeny Alfonso Rodríguez, subvalora esta noción cuando señala: "Participar es que las personas estén presentes cuando las convoquemos para una actividad. Yo participo en todo. Nosotros, los delegados, aglutinamos gente" (entrevista personal, 2011). Esta delegada de los CP circunscribe insistentemente la participación al ámbito de la cultura, evidenciando limitaciones conceptuales: "En los últimos años considero que la participación ha aumentado, porque hemos tratado de llevar más actividades culturales al barrio" (entrevista personal, 2011).

Otra concepción del acto de participar consiste en estar unidos y servir a la Revolución, calificativos con los que la arenga oficial identifica, de forma simultánea, a la nación, el Estado y el Partido. Según este discurso, en palabras de Mario Fraga Rojas,

participar es estar en la vanguardia en todo: trabajos voluntarios, donaciones de sangre, lucha contra el delito. No podemos permitir que la Revolución caiga en manos del enemigo. Tenemos que hacer lo posible por sobrevivir, pero con la participación de la gente (entrevista personal, 201I).

En este discurso tradicional, la participación podría asociarse al segundo nivel, concebido como tener parte. Sin embargo, ninguno de estos dos primeros grados va más 
allá de un involucramiento concebido como capacidad de sensibilizarse, apoyar y actuar sobre la base de decisiones ya tomadas previamente por el Gobierno.

La idea de recibir en el acto de participar es recurrente. Según entrevistados participar es recibir, ya sea información, conocimiento, autoestima, estímulos, incentivos, etc. Este aspecto es imprescindible; no obstante, se trata más de la calidad de la participación que de una forma de actuar. Comunicar, intercambiar, compartir, son otras tantas definiciones del acto de participar que afloraron a lo largo del estudio. Igualmente, se trata de un aspecto fundamental para una participación eficaz; pero la idea no corresponde al acto de participar en sí: formar y tener parte incluyen una noción de pertenencia y otra de actuación, lo que si bien pasa por la comunicación y el intercambio, no se limita a estos.

Aunque la idea de tomar parte surgió en algunas entrevistas, siempre fue expresada tímidamente por miembros de la directiva del CP, y con algo más de precisión por Andrea del Sol, la especialista principal del TTIB:

Muy pocas personas saben hasta dónde puede llegar su participación y que las personas en Cuba pueden participar genuinamente: estar presente, opinar, proponer cosas, comprometerse y tomar decisiones. El acuerdo final debe corresponderse con lo que la gente pide, $y$ eso todavía sucede pocas veces en nuestros espacios (entrevista personal, 20l I).

\section{Los desafíos de las estructuras de participación}

El CP Alamar Este recoge en su acción cotidiana quejas de los pobladores de la comunidad, documentación que podría servir para dar respuestas eficaces y de largo plazo a las necesidades de la población, en vez de resolver problemas puntuales, a corto plazo. El Poder Popular, representado por el CP, podría entonces delegar algunas decisiones y acciones en grupos de población organizados y concentrarse más en 
los problemas de fondo: se trataría de atender al poblador no como a un cliente, sino como ciudadano.

$\mathrm{Al}$ respecto se plantea, en palabras de Andrea del Sol:

Nos cuesta mucho impulsar cosas. Las trabas tienen que ver con las estructuras creadas para participar. El sistema del Poder Popular está diseñado con el objetivo de empoderar a las personas, para que tengan espacios de debates, propuestas y toma de decisiones, pero casi nunca se logra. Se dice que no hay frenos, que las personas son libres de pensar y hacer [...], pero en la práctica no se concretan las cosas (entrevista personal, 20II).

Actualmente los CP parecen limitar la participación popular directa y reforzar a escala comunitaria el protagonismo o control de los funcionarios miembros de los órganos superiores de gobierno. La consagración del papel de la participación sufre de una interpretación restringida por el rol asignado a los delegados. Dice Yeny Alfonso Rodríguez: "Eso es lo que hacemos los delegados: encaminar los problemas, porque en los consejos populares no tenemos recursos para resolverlos. Muchas veces hay un problema, nosotros sugerimos, pero en realidad es la Asamblea Municipal quien decide" (entrevista personal, 2011). Andrea del Sol, una líder señala: "La gente tiene que aprender a juntarse. Los sistemas del país no son lo suficientemente horizontales. Pero la participación de la gente puede mejorar si empezamos por sensibilizar a quienes hacen política" (entrevista personal, 2011). Desafortunadamente, ejemplos estimulantes, como el de la delegada y diputada de Micro $\mathrm{X}$ y la delegada y especialista principal del TTIB, aún no parecen constituir la regla extendida a nivel capitalino. Además, "hace falta un liderazgo en el barrio, y la gente no quiere ser líder porque eso implica responsabilidad y exige tiempo" (entrevista personal, 2011). A fin de cuentas, las iniciativas que mayormente prosperan apuntan a cierto 
"colectivismo de baja intensidad", transado a menudo por fórmulas mercantiles, que acaecen al margen de la institucionalidad y pueden conllevar formas de cierto "individualismo colectivo". ${ }^{6}$ La situación engendra simplemente un descrédito de las instituciones y una inercia total en la población con un repliegue sobre sí misma.

En las asambleas de rendición de cuentas observadas en Alamar Este, la participación de la población se limitó a la expresión de sus inquietudes y necesidades o, a veces, a la formulación de demandas. Se desconoce este mecanismo de control y de evaluación del trabajo del delegado, pues los habitantes no perciben claramente que disponen de una vía para tomar decisiones vinculantes, en cuanto al trabajo del delegado, como fórmulas de aprobación o sanción. Dice Luis Sosa Silva: "Tengo mi criterio, si me lo piden lo doy pero no evalúo el trabajo del delegado" (entrevista personal, 2011).

Aunque no es una práctica común, todos los entrevistados coincidieron en reconocer la potestad de los electores de revocar a un delegado, presidente de CP, Asamblea Municipal o provincial e, inclusive, a un diputado.

\section{Participación ante las convocatorias nacionales}

Adicionalmente, los grandes debates nacionales -como el convocado por el presidente Raúl Castro el 26 de julio de 2007, y el más reciente sobre el Proyecto de Lineamientos de la Política Económica y Social del Partido y la Revolución, 2011-, discutidos en la base y luego recentralizados a nivel de nación para la toma de decisiones, pueden resultar un mecanismo de fragmentación y dispersión de los debates.

Los testimonios nos recuerdan que Cuba posee un amplio tejido de organizaciones de masas con escenarios

6. Como la solución encontrada al desabasto de agua a partir de la obtención de recursos procedentes del mercado negro y la contratación de técnicos particulares a partir del dinero recogido por los vecinos. 
que pudieran acoger la discusión abierta de importantes problemas locales, ramales y nacionales. Sin embargo, hoy estos necesarios procesos deliberativos son escasos, muy formales o adquieren relevancia únicamente ante convocatorias emanadas de la alta dirección partidista, cuando debieran conformar una práctica común. Suponen un proceso vertical de recolección y análisis de criterios, que se van articulando y "elevando" dentro de una estructura piramidal. En estos procesos de consulta, los foros locales casi nunca se articulan; y falla la retroalimentación de lo debatido, que permitiría al ciudadano ponderar su visión y la prioridad local en el contexto general de la nación.

Aunque necesitan transformar su papel movilizador y fortalecer el papel activo del sujeto, las estructuras participativas barriales constituirían un potencial para promover la participación comunitaria, si cambiaran las prácticas burocráticas y centralistas del nivel estatal central y la injerencia del aparato partidista. Una consecuencia de la adormecida cultura participativa es la limitada concertación e iniciativa públicas canalizadas a través de instancias oficiales, observadas en la población de Alamar Este. ${ }^{7} \mathrm{Al}$ respecto, Mercedes Galán Tamayo, una activista señaló: "Fomentamos los procesos de concertación, pues los cubanos no estamos acostumbrados a concertar, a ponernos de acuerdo para realizar una tarea" (entrevista personal, 2011).

Otro problema que atenta contra la participación es la demora institucional en resolver asuntos de la comunidad y la sensación de impotencia que genera. En algunos informantes resaltó la mezcla de interés por autoorganizarse y los nocivos impactos del accionar burocrático, como comenta Mario Fraga Rojas:

7. Pues como mencionamos antes con frecuencia se acude a fórmulas privadas y/o vecinales para solucionar problemas comunitarios. 
Tratamos de resolver los problemas del barrio juntos. Pero los 'rollos gordos' corresponden al gobierno central; la solución no está en nuestras manos. La gente a veces se cansa de plantear las dificultades una y otra vez, y dejan de ir a las reuniones; se alejan de la realidad y piensan que todo es mentira (entrevista personal, 20I I).

Las reformas: alcance, realidades y pendientes

En este contexto de crisis material, desde 2008 -pero fundamentalmente a partir de 2011-el gobierno del presidente Raúl Castro ha venido impulsando un lento proceso de reformas, denominado de manera eufemística "actualización del modelo económico cubano", el cual ha generado grandes expectativas dentro y fuera de las fronteras nacionales. Las reformas -que trascienden por mucho el ámbito de la producción y los servicios- responden, en parte, a un cúmulo de añejas demandas de la población y a la necesidad de oxigenar la deprimida, ineficiente y estatizada economía de la Mayor de las Antillas.

Dentro de las transformaciones estructurales y funcionales destacan: la entrega de tierras ociosas en usufructo; la apertura a la cooperativización de actividades urbanas -construcción, comercio y servicios, fundamentalmente-; la flexibilización del objeto social de las empresas -todas estatales-; la autorización de la compra o venta de casas y automóviles entre particulares; la nueva Ley Migratoria que eliminó arcaicas restricciones para viajar; el otorgamiento de subsidios a sectores poblacionales de bajos ingresos para reparar y ampliar sus viviendas; y, por último, la Ley de Inversión Extranjera, un novedoso y polémico paquete legal que entró en vigor en julio de 2014, dirigido a atraer capitales foráneos hacia todas las ramas de la economía, excepto la Salud, la Educación y la Defensa. 
Sin embargo, en este grupo de reformas, sólo unas pocas incluyen dentro de su radio de acción el desarrollo municipal, el gobierno local y la participación comunitaria; aspectos muy deteriorados durante los últimos treinta años, tanto en la práctica como en su diseño conceptual o gubernamental. En recorridos recientes por doce de las quince provincias cubanas, ${ }^{8}$ fue posible comprobar que los municipios y pequeñas localidades del interior del país acusan graves deficiencias en materia de progreso económico, políticas sociales y prácticas participativas. En consecuencia, las estadísticas registran una tendencia creciente de las tasas de migración del campo a la ciudad, desde los pequeños territorios a las cabeceras provinciales y, sobre todo, hacia la capital del país y el extranjero. ${ }^{9}$

Respecto a la participación comunitaria y la intervención ciudadana en el gobierno local, los escenarios microsociales no escapan a la corriente macrosocial, que presenta síntomas evidentes de: 1) desmotivación entre las masas; 2) excesivos formalismo y verticalismo; 3) concepción puramente movilizativa de la participación; y, en consonancia, 4) cultura política mellada en su esencia democrática, poco activa, parroquial y subordinada, anquilosada en un modelo pseudoparticipativo.

A escala local, la participación se reduce hoy al involucramiento vecinal en tareas de saneamiento, reanimación urbana, recreación y deportes, mientras que la arista política se restringe al ejercicio individual de la voz y la agregación limitada de demandas, y no a la conformación de la agenda, mucho menos a su ejecución y control. Las correcciones, por su parte, son privativas de la voluntad de dirigentes estatales que operan -a nivel regional y local-con

8. Realizados por Lázaro de Jesús González en 2013 y 2014.

9. Cifras oficiales estiman en casi 40000 el promedio anual de jóvenes emigrados al extranjero durante el último lustro. 
casi total discrecionalidad respecto a la ciudadanía. Según un estudioso del tema:

Los delegados resultan así agentes del Estado para conformar el orden político de la comunidad y deben actuar en su beneficio y con el asentimiento de esta en el lapso que los electores le han autorizado con su voto. Si el principal es el nivel superior del Estado, el diseño hace prevalecer la soberanía estatal sobre la soberanía popular, o sea, el gobierno sobre la soberanía. En esa lógica desde arriba, el Estado se considera como el actor principal de la construcción política e imagina al Poder Popular como un instrumento para la administración (Guanche, 20I3).

Expectativas ante los cambios: ¿profecía autocumplida?

Tras la nueva división política administrativa, que entró en vigor el primero de enero de 2011, en el territorio de la periferia capitalina surgieron dos nuevas provincias: Artemisa y Mayabeque. En ellas comenzó a implementarse una prueba piloto de desconcentración del poder regional y perfeccionamiento de las estructuras y funciones del gobierno local, matizada por salpicaduras de mayor autonomía y racionalidad administrativa. La primera medida adoptada en las instituciones gubernamentales de ambos territorios fue la reducción drástica -casi a la mitad- del inflado aparato de funcionarios encargados de supervisar las distintas actividades sociales, económicas y políticas en cada demarcación. Ello, amparado en criterios de austeridad y eficiencia gerencial, así como en las reiteradas denuncias de estudios críticos sobre el funcionamiento de los órganos locales del Poder Popular.

Luego, en enero de 2012 empezó a aplicarse el principio de la separación de funciones gubernamentales y administrativas. Es decir, mientras en el resto del país la misma persona es juez y parte, pues concentra la presidencia de la Asamblea del Poder Popular -provincial o municipal- y a 
la vez encabeza el Consejo de la Administración correspondiente, en todos los municipios de Artemisa y Mayabeque -y a nivel provincial- la segunda instancia -la administrativa- la ocupa otro actor, jerárquicamente subordinado al presidente del órgano de gobierno. El propósito es que la institución encargada de legislar y gobernar se dedique a cumplir a cabalidad sus funciones, la mayoría de las veces desatendidas por el alto consumo de tiempo que exigen los asuntos administrativos.

Uno de los aspectos que se estudia y se pretende eliminar es el principio de verticalidad, harto extendido, por ejemplo, en todos los ministerios, en relación con sus direcciones provinciales, y de estas hacia los municipios. Ese tipo de mentalidad trae como consecuencia el desconocimiento de la autoridad del presidente de la Asamblea o de su Consejo de la Administración, reconoce Tamara Valido Benítez, presidenta de la Asamblea Provincial del Poder Popular en Mayabeque y diputada a la Asamblea Nacional:

A esto se suman el exceso de comisiones de trabajo que sustituyen las funciones de otros, no solucionan nada y generan reuniones innecesarias; y la elevada cantidad de vicepresidentes: un Consejo de administración local tiene veinticinco compañeros, muchos de los cuales por la función que realizan no defienden criterios estatales, sino empresariales (Chappi, 2013, p. 5).

Ante la posibilidad de su generalización al resto del país, los resultados de este experimento debían darse a conocer en diciembre de 2013; sin embargo, debido a causas desconocidas se prorrogó dicha difusión por un año más. A Julio Antonio Fernández Estrada, jurista que ha estudiado desde el punto de vista legal el proyecto emprendido en Mayabeque y Artemisa, le preocupa el excesivo énfasis en el perfeccionamiento del Consejo de la Administración, lo cual debilita el papel de las asambleas. "Es muy importante defender 
que ellas son las representantes directas del pueblo, por lo tanto, tienen que ser el órgano soberano a esos niveles" (Chappi, 2013, p. 6). El Profesor e investigador del Centro de Estudios de Administración Pública de la Universidad de La Habana critica, asimismo, que en el Decreto rector de esta experiencia -el 301-, las referencias al Consejo Popular son mínimas y la participación ciudadana en la decisión de los cambios nula.

Desde su surgimiento, estas dos provincias implementan dentro de su sistema tributario otra medida novedosa y exclusiva: la Contribución territorial para el desarrollo local, un impuesto definido centralmente, cuyo objetivo es favorecer los menguados presupuestos municipales y estimular el auge económico sobre bases sostenibles. De acuerdo con la legislación, las empresas, sociedades mercantiles y cooperativas pagan el 1\% de sus ingresos brutos a los Consejos de la Administración municipales donde operan sus establecimientos, con independencia del lugar en que radique la sede principal.

A partir de este año 2014, esta experiencia se multiplica en otros veinticinco municipios, con lo cual suman ya cuarenta y siete, casi la tercera parte del total de municipios del país. No obstante, el éxito de esta iniciativa dependerá, en buena medida, de la capacidad autogestiva de los gobiernos para reinvertir ese dinero en proyectos de desarrollo endógeno, que aporten más al capital socioeconómico del territorio. Semejante potencial está sujeto también al respaldo productivo de las endebles agricultura e industria nacionales, pues, en el ámbito microsocial, la carencia de recursos y materias primas en repetidas ocasiones frustra empeños prometedores. Tampoco ayuda la interminable espera "tramito(i)lógica" burocrática, que en la actualidad es necesaria para aprobar un proyecto de desarrollo local. Conocemos de expedientes que se cansan de "bostezar" dentro de las gavetas de varios 
Participación comunitaria y gobiernos locales en Cuba. La experiencia de los Consejos Populares y el impacto de las reformas de Raúl Castro

ministerios (sobre todo en el de la Agricultura), a la espera de la aprobación del titular de la cartera. ${ }^{10}$

Otra reforma que pudiera tener un impacto positivo en los espacios locales y la gestión del Poder Popular es el fomento del "trabajo por cuenta propia". Cuatro décadas después de la Ofensiva Revolucionaria (1968), que estatalizó hasta los más pequeñitos negocios personales, las recientes transformaciones se proponen promover el sector privado en áreas no estratégicas de la economía nacional-comercio, transporte, servicios y construcción-. Este proceso pasa por la difícil desestigmatización social de la figura del "particular", ahora reivindicado en campaña masiva por los medios de comunicación. El "cuentapropismo" pudiera convertirse en otra importante fuente de ingresos para las arcas de los gobiernos municipales, pero en la práctica enfrenta numerosos obstáculos, como: trabas jurídicas obsoletas, ausencia total de un mercado mayorista y consiguiente sujeción a los vaivenes del mercado negro, y una mentalidad anquilosada, adversa, por parte del funcionariado responsable, supuestamente, de fomentar la iniciativa privada.

\section{Conclusiones: retos para una participación comunitaria activa}

Voces identificadas con el discurso de la Revolución (Fiordelisio, 2007) suelen decir que Cuba goza de un buen nivel de cultura participativa ${ }^{11} \mathrm{y}$ ofrecen lecturas excesivamente

10. Los proyectos también duermen el "sueño eterno" en el Ministerio de Comercio Exterior e Inversión Extranjera, cuando se trata de proyectos sustentados por financiamiento internacional. Diversos informes del parlamento han denunciado reiteradamente la pérdida de valiosas inversiones foráneas, debido a las demoras en la aprobación centralizada.

I I. Ello se debe, en buena parte de los casos, a una peculiar visión que subordina el análisis científico a una visión restringida del compromiso político, que a la postre daña el proyecto político que busca defender, al desproveerlo de insumos para su autoanálisis y corrección. 
idealizadoras del fenómeno. Sin embargo, la evidencia demuestra que ello se limita generalmente a una intervención pasiva, donde la mayoría de los entrevistados concibe el proceso participativo como formar parte y tener parte, y muy pocos reconocen la necesidad de tomar parte en relación con las problemáticas. El diseño verticalista y centralizado del sistema político, así como la tradicional y acotada cultura participativa de muchos habitantes, atentan contra una verdadera participación comunitaria.

Como se ha expresado anteriormente -y este trabajo lo reafirma-, en los espacios locales y comunitarios cubanos se priorizan formas de participación consultivas, territorialmente fragmentadas y temáticamente parroquiales (Chaguaceda, et al., 2012). En las llamadas "asambleas de rendición de cuenta" del Poder Popular en los barrios, el potencial democrático se limita casi exclusivamente a emplazar por su ejecutoria a funcionarios de bajo y medio rango, con demandas que giran casi siempre alrededor de bienes y servicios insatisfechos, y no sobre procedimientos o asuntos de mayor alcance. Aunque las experiencias de remoción de representantes por electores de base tienen contados ejemplos, el protagonismo de la población en ese rubro, así como la relativamente mayor transparencia del desempeño institucional, son reales pero limitados en temas y posibilidades de control, debido a: 1) la subordinación vertical de los órganos de poder local; 2) un enfoque convencional acerca del rol del PCC como fuerza rectora de la comunidad; 3) la persistencia de estilos autoritarios y personalistas de liderazgo; y 4) la preeminencia de una participación movilizadora.

Como vimos, las escasas reformas que abarcan el ámbito del desarrollo y gobierno locales, incluida la participación comunitaria, todavía no maduran. Apenas comienzan a rendir sus primeros frutos "precosecha", trastabillando entre disímiles escollos. A diferencia del famoso teorema de Thomas que reza: "si los hombres definen las situaciones 
como reales, entonces son reales en sus consecuencias", en este caso, para transformar las circunstancias no basta con que las personas en las comunidades ansíen y se empeñen en cambiar las cosas; la tara de los factores contextuales pesa demasiado en la balanza de la compleja realidad. De tal suerte, varios principios medulares (Valencia, 2013) del quehacer y la institucionalidad en este nivel del ordenamiento político y social -la autonomía municipal, la democracia en el gobierno y la eficacia en los servicios públicos-, ven lastrados su potencial por semejantes factores estructurales e inercias mentales derivados del tipo de régimen político vigente.

En fechas recientes, el gobierno nacional ha procurado acotar la emergencia de liderazgos contestatarios y autónomos en el ámbito comunitario, mediante la combinación de acoso policial, presión social a través de los órganos de base del PCC y, en extremo, la modificación de los circuitos electorales locales (gerrymandering). En 2012, la delegada Sirley Avila, una campesina de la empobrecida zona oriental del país, ante la desatención de los distintos órganos de gobierno por su reclamo en contra del cierre de escuelas rurales en la circunscripción, acudió a la prensa independiente para denunciar lo sucedido. Fue acosada por inspectores agrarios, agentes policiales y, finalmente, en los comicios de 2013, su electorado fue disperso a partir de una operación de gerrymandering, que rediseñó ad hoc de su circuito local.

Para las elecciones de delegados a realizarse el 19 de abril de 2015, dos candidatos de oposición -el periodista independiente Hildebrando Chaviano y el activista comunitario Yuniel Francisco López O’Farril- han sido propuestos por sus vecinos, a despecho de presiones y campañas adversas del Estado. Con independencia de si resultan electos o si, una vez en funciones, pudiesen acometer con éxito su gestión, estas candidaturas revelan una arista de desafección ciudadana, que se añade a la paulatina disminución de los niveles de 
participación (expresión del cansancio y malestar ciudadano) en zonas urbanas, notoriamente en la capital del país.

Los CP, como instancias territoriales que reúnen una población inferior a la del municipio, deben servir de canales a la participación en el espacio local cubano, pero poseen limitadas atribuciones efectivas ${ }^{12}$ y aún menos recursos. Su promisoria expansión durante los años noventa no rindió lo esperado, al insertarse dentro de un orden típico de socialismo de Estado, vertical y centralizado. La superposición de espacios participativos tradicionales satura a una población cansada de insertarse en un "mar de participación con un centímetro de profundidad”. Pese a ello, la combinación de iniciativas de capacitación y concertación, los espacios de intercambio entre vecinos y una cultura política participativa mantienen cierto lugar en la Cuba actual. Algunos líderes y activistas locales enfrentan, dentro de las asimetrías y exclusiones propias de un orden autoritario, las prácticas e ideas dominantes que acotan el empoderamiento y potencial transformador de los ciudadanos cubanos.

Fecha de recepción: 25 de noviembre de 2014

Fecha de aceptación: 03 de febrero de 2015

12. Aun cuando, formalmente, la Ley 91 de los Consejos Populares les otorgue a dichas instancias facultades para propiciar y estimular iniciativas ciudadanas.

Bibliografía

AA.VV. (1998). Talleres de Transformación Integral del Barrio, una experiencia de desarrollo comunitario en la Capital. La Habana: Grupo para el Desarrollo Integral de la Capital/ Asamblea Provincial del Poder Popular.

(2006). TTIB: espacios para crecer y transformar. La Habana:TTIB Alamar Este.

Chaguaceda, A. (comp.) (2008). Participación y espacio asociativo. La Habana: Publicaciones Acuario. 
Chaguaceda, A.; Daubelcour D. y González, L. (20I2). "Community participation in Cuba: experiencies from a Popular Council”. International Journal of Cuban Studies, 4(3/4), 366-384.

Chappi Docurro, T. (28 de noviembre de 20/3). "Entre signos de interrogación”, en Catalejo, blog de la Revista Temas. Cultura, ideología y sociedad. Recuperado el 20 de enero de 2015 de http://www.temas.cult.cu/ujueves/ resUJnoviembre 13.pdf

D’Angelo, O. (2004). Autonomía integradora y transformación social: el desafio ético emancipatorio de la complejidad. La Habana: Centro de Investigaciones Psicológicas y Sociológicas.

Daubelcour, D. (2008). Entrevista personal a Adonis García, presidente del Consejo Popular Alamar Este.

Dilla, H.; González, G. y Vicentelli, A. (1993). Participación popular y desarrollo en los municipios cubanos. La Habana: Centros de Estudios sobre América.

Domínguez, M. I. y Lutjens, S. L. (2004). “La Federación de Estudiantes de la Enseñanza Media (FEEM) y la participación estudiantil en Cuba", en Pérez García, A.J. (comp.), Participación social en Cuba (pp. 23I-256). La Habana: Centro de Investigaciones Psicológicas y Sociológicas.

Fals Borda, O. (200I). “Algunos ingredientes básicos”, en AA.VV., Selección de lecturas sobre Investigación Acción Participativa (pp. 30-57). La Habana:Asociación de Pedagogos de Cuba.

Fiordelisio, M. (2007). Poder Popular y autogobierno en Cuba. La Revolución desde el municipio. México, D. F.: Editorial Ítaca. García Brigos, J. (1998). Gobernabilidad y democracia, los Órganos del Poder Popular en Cuba. La Habana: Editorial Ciencias Sociales.

González, L. (20I I). Entrevista personal a Andrea del Sol Leyva, especialista principal del Taller de Transformación Integral del Barrio Alamar Este. 
Bibliografía (20II). Entrevista personal a Blanca Ballester Santos, diputada a la Asamblea Nacional y delegada de circunscripción del Consejo Popular Alamar Este.

- (20II). Entrevista personal a Luis Sosa Silva, director del Policlínico Enrique Betancourt Neninger, Alamar Este.

(20II). Entrevista personal a Mario Fraga Rojas, delegado de circunscripción del Consejo Popular Alamar Este.

(20II). Entrevista personal a Mercedes Galán Tamayo, especialista del Taller de Transformación Integral del Barrio Alamar Este.

(20I I). Entrevista personal a Yeny Alfonso Rodríguez, presidenta del Consejo Popular Alamar Este.

Guanche, J. C. (20I3). Estado, participación y representación política en Cuba diseño institucional y práctica política tras la reforma constitucional de 1992. Buenos Aires: CLACSO. Recuperado de http://bibliotecavirtual.clacso.org.ar/ clacso/becas/20 I 20420 I I 2357/guanche20 I I05.pdf

Linares, C.; Moras, P.y Rivero, Y. (comps.) (2004). La participación diálogo y debate en el contexto cubano. La Habana: Centro de Investigación y Desarrollo de la Cultura Cubana Juan Marinello.

Pérez García, A. J. (comp.) (2004). Participación social en Cuba. La Habana: Centro de Investigaciones Psicológicas y Sociológicas.

Pupo, P.y Santana, A. (2005). La comunidad de Alamar Este. La Habana: Grupo para el Desarrollo Integral de la Capital/ Asamblea Provincial del Poder Popular.

Rebellato, J. L. (2005). “La participación como territorio de contradicciones éticas (segunda parte)”, en Hernández, C. N. (comp.), Trabajo comunitario. Selección de Lecturas (pp. 457-480). La Habana: Caminos.

Valencia Carmona, S. (20I3). Derecho Municipal.México, D.F.: Universidad Nacional Autónoma de México/Editorial Porrúa. 